\title{
Selecting the Right Donors - Still a Challenge: Development of a Uniform Donor Questionnaire in Germany
}

\author{
Ruth Offergeld ${ }^{\mathrm{a}}$ Margarethe Heiden ${ }^{\mathrm{b}}$ \\ a Department of Infectious Disease Epidemiology, Robert Koch Institute, Berlin, Germany; \\ ${ }^{b}$ Department for Transfusion Medicine, Paul Ehrlich Institute, Langen, Germany
}

\section{Keywords}

Blood donors · Blood safety · Surveys and questionnaires

\section{Summary}

The selection of blood donors includes the assessment of the individual's health and medical history by using a donor questionnaire (DQ) in order to identify persons whose donation could present a health risk to recipients or to themselves. This way, DQs provide one layer of blood safety and contribute to the high safety profile of blood components currently available in Germany. This review reports the development of a new uniform questionnaire in Germany and its first evaluation using a field test approach. This development is set in context with the international experiences regarding donor selection and prospective challenges.

(C) 2017 S. Karger GmbH, Freiburg

\section{Introduction}

The use of a questionnaire to assess donor eligibility is mandatory in the European Union [1]. Recently, mathematic modelling confirmed that exclusive reliance on screening blood donations with NAT could result in an estimated fourfold increase in the annual number of HIV-positive units collected during the window period in the US [2]. The benefit of questionnaires is even more pronounced with respect to the prevention of transfusion-transmissible infections with emerging or re-emerging pathogens for which testing is not available [3].

\section{KARGER}

(C) 2017 S. Karger GmbH, Freiburg

\section{Donor Selection in Germany}

In Germany, donor questionnaires (DQs) are until now almost exclusively self-administered paper-based questionnaires which include all questions needed for the decision about donor eligibility. No subject of the DQ is routinely dealt with in an oral interview only although some aspects might be touched during the mandatory medical examination, especially in case of doubt.

The licensing procedure for blood components includes approval of the DQ by the competent authority, the Paul Ehrlich Institute (PEI). All DQs must cover the eligibility criteria for donors as laid down in the German Hemotherapy Guidelines [4].

In the absence of a national blood service, each of the more than 100 blood establishments or their respective organizations drafted their own DQ. The various DQs developed over time. Questions were added or modified mainly to meet regulatory requirements. Sometimes, practical issues lead to multiple-item questions, e.g. in order to include all questions on a single sheet of paper. The different DQs contained as many as 68 or as few as 17 questions when an expert group considered the development of a uniform questionnaire in 2004. This expert group initially consisted of members of the National Advisory Committee 'Blood' (AK Blut), the Society for Immunohematology and Transfusion Medicine (DGTI), the Professional Society (BDT), the PEI, and the Robert Koch Institute (RKI), the National Public Health Institute.

The chief goal of a uniform questionnaire was to set a standard for the translation of the European and national requirements regarding donor selection and to contribute to quality management. As an additional advantage for blood establishments, it was envisaged that the national DQ would be hosted and maintained by the PEI and thus end the need for keeping an in-house DQ up to date. Also, it would reduce the effort of the licensing authority to review each change to a DQ for every blood establishment. 
Blood donations and blood products in Germany are very safe. Only few confirmed HIV-, HCV- or HBV-positive donations are detected $[5,6,7,8]$, and only very few confirmed transmissions of pathogens are reported each year [9]. Still, data from post-donation interviews revealed that a majority of HIV-, HCV- or HBV-positive donors would not have been allowed to donate if they had indicated their risks or exposure in the pre-donation process. This pointed to room for improvement with respect to DQs.

The development of a national DQ started with a review of the existing national and international questionnaires, and it became obvious that the blood establishments had taken different paths: Some developed a short and concise DQ, whereas others included all donor selection items of the Hemotherapy Guidelines, mainly in multiple-item questions. Often only one answer was to be provided for as many as 10 or 15 health issues.

\section{Designing a Good Questionnaire}

DQs are always in an area of conflict between completeness with respect to donor selection criteria, liability exclusion, comprehensibility, donor satisfaction, adequate donor deferrals, feasibility, practicability and satisfaction of the personnel.

Realizing this, the next step in the development of a national DQ included the review of the 'Good Questionnaire Practice' (GQP). The art of designing a good questionnaire in general is not an easy one but even more difficult when it contributes to the production of a licensed drug.

Basic rules for questionnaires in this setting include $[10,11]$ :

- Keeping the questionnaire short.

- Avoiding technical terms and jargon.

- Avoiding complex sentences.

- Avoiding questions using leading, emotional, or evocative language.

- Avoiding double-barreled questions.

- Defining issues specifically.

- Using ordinal scales.

- Choosing answer choices which anticipate all possibilities.

Adherence to these rules will help to collect information from the respondent as correct as possible.

On the side of the donor, four basic tasks are needed in order to respond to questions on a questionnaire: interpretation, memory retrieval, judgment format, and response editing [12]. To reduce the degree of unwanted interpretation of a question, predominately closed ended questions are used in a DQ. These ensure, if well designed, that prospective donors interpret questions in the same way. To enhance memory retrieval and to ask about all potential risks, the various medical conditions relevant for donor selection are commonly listed with their respective technical terms, e.g. in a list of infectious diseases. This interferes with some of the aspects of the GQP, namely the avoidance of technical terms (GQP rule no. 2). Likewise, fulfilling GQP rule no. 5 and asking for the various relevant infectious disease risks with separate questions will hurt rule no. 1 keeping the questionnaire short. If in- stead a number of medical conditions are asked for with one possible answer only, this type of question bears the risk of nonattendance or of being a double-barreled (GQP rule no. 5). This was observed in the evaluation of the Canadian DQ [13]. In this study, donors were asked in a structured interview immediately after donation if they remembered questions of the DQ. It became evident that blood donors chiefly forgot the content of multi-item questions. This indicates that these questions are more difficult for people to attend to, especially if technical terms are used. In addition, individuals faced with multiple items in a written question tend to think about the first item more carefully than the following ones $[14,15]$. The aspect of judgment format is less relevant in a DQ as donors are not asked about their opinion on certain issues. Still, judgment may influence the response editing of donors, especially when personal topics are covered like sexual risk behavior.

\section{Development of the Uniform Donor Questionnaire in Germany}

Keeping these aspects in mind, a first version of the uniform donor questionnaire was developed by the expert group. Several reasonable compromises had to be made in order to meet all the needs of the blood establishments and the competent authority. For instance, it was decided to omit the possibility of a 'don't know' answer, this way not all possible answer choices were available for the donor (GQP rule no. 8). It was assumed that a 'don't know' answer would lead to more insecurity among unexperienced donors and to unnecessary extra work for the staff. Some multipleitem questions were also included despite the known disadvantages in order to include all required donor eligibility criteria. This was done especially for the medical history. The option to design a capture question like: 'have you had any severe infectious disease' was also discussed but dismissed. To answer such a question, the donor would first of all need to know, what an infectious disease is and secondly interpret the term 'severe' in the context of a blood donation. It became very clear that in addition to all aspects of good questionnaire practice the main focus was set on leaving as little interpretation to the donor as possible in answering the questions in the DQ.

While capture questions were not suitable for the medical history, they were chosen for other issues like travel history. The question 'have you travelled abroad in the past 12 months' is unambiguous and easy to answer rather than asking for certain areas ('tropical region') or for endemic areas of certain diseases like 'malariaendemic region'. In order to guide the interpretation of this and other capture questions, the first version of the uniform DQ also included a second level of information for the blood bank physician to provide additional information on specific aspects of the deferral criteria. For example, information was provided on the different time periods for deferral after travelling abroad (e.g. 4 weeks after travelling to West-Nile virus-endemic regions, 6 months after travelling to malaria-endemic regions). 


\section{Special Focus on Sexual Risk Behavior}

In the evolution of the uniform DQ, special attention was laid on the assessment of sexual risk behavior. A European expert group of the European Directorate of Qualities in Medicine and Healthcare (EDQM) tried to define different risk categories for sexual behavior. It was concluded that existing data confirm that men who have sex with men (MSM) and commercial sex workers (CSW) are groups at high risk but that any further grading lacked a scientific database $[16,17]$. Still, analysis of the epidemiological data from donors revealed that almost all donors who tested positive for $\mathrm{HIV}, \mathrm{HCV}$, $\mathrm{HBV}$, or syphilis predominantly reported sexual risks or exposures that would have led to deferral if they had been known at the time of donation [5-8]. These donors included MSM as well as heterosexuals. The established DQs in Germany frequently used leading questions to assess sexual risks, especially heterosexual risk. In some instances sexual risk behavior was defined only in the donor educational material, and the question in the DQ referred to this list asking if the donor had any risks listed in the information leaflet. This may have opened room for interpretation on the side of the donor. Precise explanation of what is meant by sexual activity is also of relevance. The definition of sexual behavior in the context of a donation was analyzed in a study in Canada. Donors were asked to pick those sexual activities from a list that they felt were meant by 'sex' in the DQ [18]. It turned out that the definitions of 'sex' were not uniform, albeit most donors included the sexual practices relevant for blood safety. It was observed that the donor educational material had little impact on the individual's definition of sex in the study. Instead, the donor's believes and their rating of relevance for the safety of the donation turned out to be more important (need for GQP rules no. 4 and 6). The personal perception of risk has been identified as one of the main reasons for non-self-deferral in heterosexuals as well as in MSM. In an Italian study, HIV-positive donors reported sexual risk behavior in the post-donation interview. When asked why they had not reported this prior to donation, twothirds stated that they felt they had not engaged in at-risk behavior [19]. A cross-sectional survey in the UK demonstrated that some MSM with recent sexual risks also donated because of their selfcategorization as 'low risk'. Furthermore, the belief that blood screening is infallible and concerns about the confidentiality of their answers were given as reasons for non-disclosure [20]. This was confirmed in a Dutch study assessing the percentage of donating MSM and their reasons for non-compliance [21]. Recently, a study in the US was able to demonstrate that donors fill in the DQ framed by the questionnaire's general purpose rather than the specific topic of the individual questions. This pattern of interpretation was the key factor responsible for both false-positive and false-negative response errors and included sexual risk behavior [22].

The design of the uniform DQ in Germany therefore included a plain question about sex between men (permanent deferral in place at the time of the study) and a simple, non-judgmental question on exposure rather than risk with respect to heterosexual activity. Potential donors were asked if they had unprotected sex with a new partner in the 4 months preceding the donation. The group de- cided to use this question instead of arbitrarily defining a crucial number of partners per time period (GQP rule no. 7) without evidence or using leading questions like 'frequent change of partner' (GQP rule no. 4). This approach was chosen in order to minimize the influence of interpretation on the side of the donor and to include all possible modes of infection. As a consequence, some donors without increased sexual risks would be deferred for 4 months as well. This was accepted because of the good experience in other European countries [16] and in view of the analysis of the post-donation interviews. In the evaluation of the Canadian DQ, however, a question like this, especially if formulated as a gender-neutral question, was not included as it was believed to lead to deferral of many safe donors [23]. The potential loss of predominantly young donors due to this question was investigated further in the evaluation of the German DQ.

\section{Evaluation of the Donor Questionnaire}

Once the first version of the DQ was drafted, the group decided to evaluate the DQ before it was presented to the AK Blut for approval. Until this time, German DQs had not been scientifically evaluated. It became clear that an evaluation should ideally include different outcome measures like comprehensibility, feasibility for the blood establishment, donor satisfaction, deferral rates, and last but not least compliance. The latter proved to be extremely challenging. In search of a format for the DQ evaluation, randomized controlled trials using different $\mathrm{DQ}$ versions were not an option since the DQ is part of the licensing procedure for blood products.

\section{International Approaches}

Instead, two qualitative research methods have internationally been used for the evaluation of DQs: focus group analysis and cognitive interview evaluation $[24,25]$. In a focus group, interviewers can study participants in a conversation-like situation rather than a face-to-face interview. In the evaluation of seven questions asked in the DQ of the American Red Cross, potential male and female blood donors with different cultural, ethnic and educational background were asked to give their opinion on content, clarity, likelihood of asking for more information, suggestions for improvement, and how a need for clarifying information would best be met [26]. As a result of this process, these focus groups provided valuable information and suggestions regarding several aspects of the donation process. These included specific suggestions for the clarification of technical terms and the rewording of questions to enhance donor comprehension. Still, focus group methodology is not without limitations. One disadvantage is that the process of the group discussion can unintentionally also influence participants' opinions [27]. Also, results gained in a group discussion may not exactly reflect the situation of a donor who gives answers on a DQ individually. Therefore, an additional qualitative method was cho- 
sen for redesigning and testing the American Association of Blood Banks DQ [28]: cognitive interview evaluation. This research method is a useful approach for exploring in depth the intention and meaning of survey questions to the target cohort - in this case donors $[29,30]$. Participants are asked to complete the DQ and undergo in-depth face-to-face interviews with a trained professional afterwards to identify problems with comprehension, recall, and potential response bias. In this US study, 35 individuals (non-donors representing first time donors (FTDs) and deferred donors) interviewed. Special attention was paid to include all age groups, ethnicities, and educational levels. These interviews resulted in further amendments of the DQ. Most of the issues identified by participants were easily addressed by minor wording changes, splitting up of some questions, or expanding supplemental documents such as educational materials or by providing lists, guidelines, and definitions to donor screening personnel. Finally, the authors drafted a revised version which was to their opinion thorough and simple.

In Canada, a field test approach was used to test the DQ under realistic conditions [13]. Donors were asked to be interviewed orally by a member of staff immediately after completing the DQ. Donors were asked if they recalled specific questions or items in the DQ. In addition, information was collected on donation history, demographic information, and the donor's views on administration of the DQ. Only a small percentage of donors were able to recall all items. Recall was especially reduced for items that were part of a list. The investigators concluded that the format of DQ in use at the time was not optimal. They felt that this study method had advantages over a qualitative approach, mainly because of the large number of study participants and the possibility to standardize methods of performing interviews. Also, the study setting is similar to an actual blood donor collection site.

\section{Evaluation in Germany}

We also selected a comparative field test approach for our study because it is important to understand donor attention within the context of a blood donation at a collection site [31]. Our study was designed to address donor deferrals and donor compliance as well as donor satisfaction with the DQ and potential changes in the workflow of the blood drive. Five blood establishments participated in the study: German Red Cross Blood Donation Service West in Hagen, German Red Cross Blood Donation Service BadenWürttemberg - Hesse in Mannheim German Red Cross Blood Donation Service East, Saxonia, German Red Cross Blood Donation Service Bavaria and the Department of Transfusion Medicine and Hemostaseology, University of Erlangen.

According to the study design, FTDs were either given the blood establishment-specific (EDQ) or the new uniform DQ (NDQ) by order of appearance. They completed the DQ and were asked to complete an additional questionnaire which included demographic data and scaled questions about the understandability of the question, the usefulness of the information material provided, and the sensitive nature of the topics queried. Also, some questions were asked about the donors' knowledge about deferral periods and testing of donations with respect to infectious diseases. To assess the need for additional explanation, they were asked if they had further questions or if they did not answer all questions or changed their answer in the DQ. After completing the DQ, FTDs in Germany are routinely interviewed and examined by a blood bank physician who finally decides about donor eligibility. To check for compliance with the DQ the physicians in our study initiated the contact with the new donor by performing a standardized interview. This contained eight important issues of the DQ: Travel history, medication, disease/surgery, former exclusion from blood donations (i.v. drug use, new sexual partner, no condom use, sex between men). Finally, deferrals and categorized reasons for deferral were recorded. Categories included medication, chronic disease, acute illness, travel history, pregnancy/breast feeding, risk for CJD/vCJD, risk for HIV, HCV, HBV, new sexual partner, other and pre-donation (laboratory) results.

\section{Results of the First Donor Questionnaire Study}

During 1,087 blood drives 6,502 FTDs participated in the study between 2006 and 2007. Of the 6,502 donors included in the study, $6,258(96.2 \%)$ filled in the additional questionnaire. In general, donors rated both types of questionnaire as generally understandable but a significantly higher percentage of donors rated the NDQ as highly understandable $(75.5 \%$ vs. $71.1, \mathrm{p}<0.001)$. While there was no difference in the rating of the information material, a significant difference was seen for the sensitive nature of the questions: $5.2 \%$ of donors who used the NDQ rated the questions as too personal opposed to $4.2 \%$ with the EDQs $(\mathrm{p}=0.1)$. Significantly more male donors perceived the questions as too intrusive in both types of DQs $(\mathrm{p}<0,001)$.

The majority of all donors (88\%) knew that donations would be screened for HIV, HCV, HBV, and syphilis but only $55 \%$ of donors knew that tests could not identify very recent infections revealing the need to stress this issue in the educational material. After completing the interview, roughly $16 \%$ of all donors had additional questions which they wanted to address with the blood bank physician. Three quarters of the donors had not changed any answer in the DQ, and the same proportion had not left any question unanswered.

For all issues the concordance of answers between the DQ and the personal interview was high and ranged from 92.1 to $100 \%$ for all types of questionnaires. Donors had the greatest difficulties in answering the questions about medication (92.5\% (NDQ) and $92.0 \%$ (EDQ) concordance). A significant difference in favor of the NDQ was found for the capture question about travel history: $2.5 \%$ (NDQ) and 3.4\% (EDQ) of donors said they had given an incorrect answer because they had not understood the question $(\mathrm{p}=0.04)$. Interestingly the answers to the question about sexual contacts between men differed in both questionnaire types, albeit not significantly. The EDQs did not contain a specific and direct question about MSM behavior. The clear question in the NDQ led to $100 \%$ concordance between the DQ and the interview. With the EDQ, 19 
Table 1. Reasons for deferral with the NDQ and the EDQ

\begin{tabular}{|c|c|c|c|c|c|}
\hline \multirow[t]{2}{*}{ Reasons for deferral } & \multicolumn{2}{|c|}{ NDQ } & \multicolumn{2}{|c|}{ EDQ } & \multirow[t]{2}{*}{ Difference \% } \\
\hline & $\mathrm{n}$ & $\%$ & $\mathrm{n}$ & $\%$ & \\
\hline Medication & 206 & 6.3 & 191 & 6.0 & 0.3 \\
\hline Chronic disease & 48 & 1.5 & 45 & 1.4 & 0.1 \\
\hline Acute illness & 194 & 6.0 & 105 & 3.3 & $2.7^{*}$ \\
\hline Travel history & 50 & 1.5 & 55 & 1.7 & 0.2 \\
\hline Pregnancy/breast feeding & 12 & 0.4 & 6 & 0.2 & 0.2 \\
\hline Risk CJD/vCJD & 7 & 0.2 & 9 & 0.3 & 0.1 \\
\hline Risk for HIV/HCV/HBV & 89 & 2.7 & 78 & 2.5 & 0.2 \\
\hline New sexual partner & 78 & 2.4 & 31 & 1.0 & $1.4^{*}$ \\
\hline Other ${ }^{\#}$ & 194 & 6.0 & 173 & 5.5 & 0.5 \\
\hline $\begin{array}{l}\text { Predonation laboratory results } \\
\text { (e.g. Hb, blood pressure, weight) }\end{array}$ & 39 & 1.2 & 32 & 1.0 & 0.2 \\
\hline
\end{tabular}

male donors gave incorrect answers. When interrogated why they had not given the correct information, 6 claimed they had not understood the question, 2 said they had forgotten to give the information, and 11 refused to disclose this information. This demonstrated the need for clear and unambiguous questions about sexual risk activities.

We also analyzed the proportion of donors with a confidential self-exclusion (CSE). Overall, less than $1 \%$ of donors used the CSE but significantly more men who used the new DQ stated confidentially that their donation should not be used $(\mathrm{p}=0.08)$. We believe that addressing sexual behavior/exposure directly in the DQ might have contributed to the higher proportion of male donors with a CSE.

Deferral rates were significantly higher with the NDQ; $28.1 \%$ (NDQ) and 23.5\% (EDQ) of FTDs were deferred ( $p<0.001)$. Categorized reasons for deferral are listed in table 1.

The majority of additional deferrals with the NDQ were due to acute illness (2.7\% additional deferrals) and a new sexual partner ( $1.4 \%$ additional deferrals). This was perceived as a reasonable way to avoid potential harm to the donor and risk for the recipient without a disproportionate loss of predominantly young FTDs (median age 25 years in both groups).

The results were presented to the AK Blut who published a vote in 2010 recommending the use of a uniform questionnaire which should be updated by an expert group under the aegis of the PEI [32]. After the vote of the AK Blut, an expert group was built to keep the NDQ up to date. This group included experts from blood establishments, the PEI, und the RKI. Initially a few amendments were made after the consultation in the AK Blut and the experience of the study. One amendment included the change of the new partner question. The study had shown that asking for condom use ('safer sex') in the context of a DQ proved difficult. Some donors and also some members of staff were reluctant to address this detail of sexual activity. Also, data from various studies in MSM and heterosexuals $[33,34]$ showed that condom use was inconsistent. It seemed impractical to assess the correct and consistent condom use for every sexual contact in an interview with a potential donor, and therefore the group rated a question about safer sex as inappropriate to ensure product safety. Hence, the new partner question was modified to include all new sexual contacts irrespective of condom use.

The potential loss of young donors due to the new partner question raised considerable concern among blood establishments and the scientific society. It was advocated that more data should be collected before a uniform DQ became mandatory to ensure that the donor loss would not outweigh the potential gain in blood safety. Also, blood establishments feared that repeat donors who were not subject of the evaluation study would become reluctant to donate in the future because of the direct questions regarding their sexual activities. Some opposition was also expected from staff members, especially from volunteers.

A second study was initiated by the expert group which included more than 220,000 FTDs and repeat donors. The results are presented by Houareau et al. [35] in this issue, and they confirmed most of the results of the first DQ study.

\section{Additional Donor Questionnaire Studies}

A separate investigation was performed in a large blood establishment [36]. In this study, a descriptive comparative analysis of deferral rates of more than 64,000 (EDQ) and 71,000 (NDQ) whole blood donors confirmed significantly increased proportions of deferred donors with the NDQ. The deferral rate increased by $1.9 \%$ and affected mainly female and younger donors and FTDs to a greater extent. The authors raised the point that this might have a substantial impact on future blood supply because donors who are deferred temporarily, especially FTDs, are unlikely to return to donate [37]. This may become relevant in view of the demographic changes in Germany. These will most likely lead to a decreasing donor population and an increasing need for blood products in elderly patients in the future [38]. The loss of donors due to an increase in deferrals must be weighed up against the benefits of a better identification of donors with risks for transfusion-transmissible 
infections. In this study the frequency of the CSE and deferrals due to sexual risk behavior increased as well as deferrals due to other medical conditions. As this study only compared deferrals and CSEs in the first month after the implementation of the NDQ to a historic period, some effects might be the result of the novelty of the NDQ. After the introduction of the NDQ in some blood establishments, donors and members of staff expressed their opposition, also in local newspapers and social media [39]. As a consequence, one large blood establishment even decided to return to their EDQ [40]. The most problematic issues were the questions about sexual activities. This raised concern that - apart from the additional deferrals - some donors might refrain from donating and even dissuade others from donating due to the felt private nature of the NDQ. This effect was addressed in two studies: In the first study a random sample of 6,600 donors were asked to participate in a mail survey and to rate satisfaction with the NDQ as well as the intention to return for further donations [41]. The participants were asked to answer scaled questions about format and layout of the DQ, clarity of the questions, the scope of the questionnaire, and their perception of the questions about sexual risk behavior. In this survey, donors expressed high satisfaction with format, layout, and clarity of the questions. In contrast, satisfaction was low with the scope of the NDQ and the questions about sexual risk behavior. Low satisfaction with these aspects of the NDQ was associated with a reduced intention to return for further donations, especially among experienced donors.

In a second study roughly 4,000 donors were included in a cross-sectional study of two blood establishments which also participated in the initial evaluation of the NDQ [42]. They were asked to complete an anonymous paper-based questionnaire containing questions about donor comfort with intimate questions dealing with sexual activities and the possible impact on participants' willingness to participate in future. Other questions addressed aspects of the layout, the understandability, and the perceived ability of the DQ to contribute to blood safety. The authors concluded that the NDQ was sufficiently accepted in the German blood donor population. They identified male gender, older age, and lower educational background as risk factors for being lost from the donor pool due to the explicit nature of questions about sexual activities.

Donor education should aim at explaining the need for accurate risk assessment to avoid unnecessary donor loss. This should ideally be done in a personalized interview. In this conversation, the member of staff should listen to and address the donor's objections. This strategy has proven to be more successful in donor retention than any other commonly used method like reminders or special incentives [43].

It was also demonstrated that donors' attention to reading materials is suboptimal, especially in FTDs. In a Canadian study, qualitative interviews demonstrated that donors are reluctant to read any more than necessary and base their decision on reading something carefully on the perceived importance or relevance of the topic [44]. It may also be wise to assure that the staff also agrees with new questions and to improve their skills in communicating about sexual risk behavior, e.g. by collaborating with the local AIDS Service Organization.

\section{Computer-Assisted Donor Questionnaires}

One option to avoid irritation due to personal questions and to increase compliance could be the use of other methods to assess donor risks. In Canada, the more sensitive questions were formerly not included in the self-administered DQ but addressed in the oral interview $[45,46]$. This was abandoned because - different from earlier studies [47] - no changes of HIV or HCV infection rates or of rates for permanent deferrals were observed. Instead, personal interviews for sensitive questions may even increase the likelihood of non-disclosure because of the lack of privacy. Confidentiality is very important to donors in all stages of the donation process $[17,19,20]$. This was also confirmed by freetext comments of the participants of the first DQ study. To ensure the needed degree of confidentiality in the donor health assessment, computer-assisted DQs (CADQ) could be an option. These can be conducted with text questions displayed for reading on the monitor and answers entered by the respondent. Additionally, audio presentation of the interview questions can support understanding of the text as well as illustrations when appropriate. Attractive features of a CADQ are the possibility of 'help' functions, mandatory steps in answering to ensure completeness, and additional questions which appear to complement initial answers (like type of medication). After completion, the CADQ could be printed if a paper-based signature is favored. Data of the questionnaire could be transferred electronically to the blood establishment's database.

Computer-assisted interviewing for socially sensitive or stigmatizing issues has found to be more effective in a number of studies [48]. Katz and colleagues [49] found convincing evidence in various studies that CADQs can also increase the accuracy and efficiency of the blood donation process. Compared to oral interviews and self-administered DQs, CADQs were able to identify significantly more deferrable donors. It is likely that this will lead to an increase in blood safety, although direct measurement of this increase is difficult, given low rates of donor infection rates. In a recent cross-sectional study in Brazil, $901 \mathrm{HIV}$-negative blood donors were interviewed with a CADQ after donation [50]. Donor eligibility was primarily assessed by oral interviews. $13 \%$ of donors disclosed a risk only with the CADQ that would have resulted in deferral. The main risk factors identified were sexual risk behaviors like recent unprotected sex with a nonsteady partner, multiple sexual partners, and recent contacts between men. Younger donors were more likely to disclose this information with the CADQ only. In Canada, the evaluation of different forms of donor questioning also revealed that recall of questions was best by donors who received the CADQ [51]. Still, using CADQs especially on mobile blood drives would be a challenge. Furthermore, data protection issues, authorization of documents, and the mode of record keeping for the compulsory period would need to be settled. Eventually, donor and staff satisfaction with a CADQ should be analyzed if it should be implemented in Germany. 


\section{Abbreviated Donor Questionnaires}

Another option to improve donor selection by complying better with the GQP rules could be the development of an abbreviated questionnaire for regular donors. This would help to keep the questionnaire short (GQP rule no. 1) and attention of the donor focused on the most relevant questions. In the US, an abbreviated DQ has been approved since 1998, and this approval was renewed for the most current version in 2016 [52]. Naturally, an abbreviated DQ should also be evaluated scientifically if it is to be introduced.

\section{Conclusion}

The newly developed NDQ in Germany - even in a paper-based version - has proved to be understandable, accepted by the majority of donors, and effective in collecting the information needed for the decision about donor eligibility. It contributes to a nationally harmonized donor selection. The increased deferral rates due to non-judgmental questions about sexual exposure rather than risk need to be monitored. The advantages of the NDQ must prevail over the disadvantages. International experience showed that further amendments could be helpful with respect to mode of administration and evaluation of a CADQ and the development of abbre- viated DQs for regular donors. In the development of DQs, it is of utmost importance to include all involved parties: donors, staff, and the competent authority.

\section{Funding}

Funding for data entry and evaluation for the first DQ study was provided by the German Association for Immunohematology and Transfusion Medicine (DGTI).

\section{Acknowledgement}

The authors would like to thank the former head of the uniform questionnaire expert and study group, Prof. Dr. Hinnak Northoff as well as all other members of the group. We would also like to thank the blood establishments who participated in the first evaluation of the new DQ: German Red Cross Blood Donation Service West in Hagen, German Red Cross Blood Donation Service Baden-Württemberg-Hessen in Mannheim German Red Cross Blood Donation Service East, Saxonia, German Red Cross Blood Donation Service Bavaria and the Department of Transfusion Medicine and Hemostaseology, University of Erlangen.

\section{Disclosure Statement}

Both authors declare that that they have no conflict of interest.

\section{References}

1 COMMISSION DIRECTIVE 2004/33/EC of 22 March 2004 implementing Directive 2002/98/EC of the European Parliament and of the Council as regards certain technical requirements for blood and blood components. http://eur-lex.europa.eu/LexUriServ/LexUriServ. do? uri=OJ:L:2004:091:0025:0039:EN:PDF (last accessed July 6, 2017).

2 Yang H, Anderson SA, Forshee R, Williams A, Epstein JS, Marks PW: Modeling complete removal of risk assessment questions in the USA predicts the risk of HIV exposure in blood recipients could increase despite the use of nucleic acid testing. Vox Sang 2016;110:324-328.

3 Lin C, Leung J, So B, Lee C: Donor selection for blood safety: Is it still necessary? ISBT Sci Ser 2014;9:26-29.

4 Bundesärztekammer: Richtlinien zur Gewinnung von Blut und Blutbestandteilen und zur Anwendung von Blutprodukten (Hämotherapie). Cologne, Deutscher Ärzte-Verlag, 2010

5 Offergeld R, Ritter S, Hamouda O: HIV-, HCV-, HBVund Syphilissurveillance unter Blutspendern in Deutschland 2008-2010. Bundesgesundheitsbl Gesundheitsforsch Gesundheitsschutz 2012;55:907-913.

6 Offergeld R, Ritter S, Quabeck L, Hamouda O: Infektionsepidemiologische Daten von Blutspendern in Deutschland 2007, Bundesgesundheitsbl Gesundheitsforsch Gesundheitsschutz 2010;53:1188-1196.

7 Willand L, Ritter S, Reinhard B, Offergeld R, Hamouda O: Infektionsepidemiologische Daten von Blutspendern 2006. Bericht des Robert Koch-Instituts zu den Meldungen nach $\$ 22$ Transfusionsgesetz. Bundesgesundheitsbl Gesundheitsforsch Gesundheitsschutz 2008;51:902-914.
8 Offergeld R, Ritter S, Hamouda O: Infektionsepidemiologische Daten von Blutspendern 2005. Bericht des Robert Koch-Instituts zu den Meldungen nach $\$ 22$ Transfusionsgesetz. Bundesgesundheitsbl Gesundheitsforsch Gesundheitsschutz 2007;50:1221-1231.

9 Funk M, Lohmann A, Spranger R, Witzenhausen C, Müller S, Schönefeld S, Halbauer J, Wesp K, Heiden M, Henseler O, Hanschmann K, Keller-Stanislawski B: Haemovigilance report of the Paul Ehrlich Institute 2013/2014. www.pei.de/SharedDocs/Downloads/vigilanz/haemovigilanz/publikationen/haemovigilance-report-2013-2014.pdf?_blob=publicationFile $\triangleleft v=6$ (last accessed July 6, 2017).

10 Payne SL: The Art of Asking Questions. Princeton, Princeton University, 1980.

11 Sudman S, Bradburn N: Asking Questions: A Practical Guide to Questionnaire Design. San Francisco, JosseyBass, 1982

12 Strack F, Martin FF. Thinking, judging and communicating: a process account of context effects in attitude surveys; in Hippler H-J, Schwarz N, Sudman S (eds): Social Information Processing and Survey Methodology. New York, Springer, 1987, pp 123-148.

13 Goldman M, Ram SS, Yi QL, O’Brien SF: The Canadian donor health assessment questionnaire: can it be improved? Transfusion 2006;46:2169-2175.

14 Sudman S, Bradburn NM, Schwarz N. Thinking about Answers: THE Application of Cognitive Processes to Survey Methodology. San Francisco, Jossey-Bass, 1996.

15 Krosnick JA, Alwin DF: An evaluation of a cognitive theory of response-order effects in survey measurement. Public Opin Q 1987;51:201-219.
16 Offergeld R, Heiden M, Kamp C, Norda R, Behr-Gross ME: Sexual risk behaviour and donor deferral in Europe. Vox Sang 2014;107:420-427.

17 Council of Europe : Project TS057: Risk Behaviours Having an Impact on Blood Donor Management and Transfusion Safety. www.edqm.eu/en/Project-TS0571564.html (last accessed July 6, 2017).

18 O’Brien SF, Ram SS, Yi QL, Goldman M: Donor's understanding of the definition of sex as applied to predonation screening questions. Vox Sang 2008;94;329-333-

19 Raimondo M, Facco G, Regine V, Pupella S, Grazzini G, Suligoi B: HIV-positive blood donors unaware of their sexual at-risk behaviours before donation in Italy. Vox Sang 2016;110:134-142.

20 Grenfell P, Nutland W, McManus,Datta J, Soldan K, Wellings K: Views and experiences of men who have sex with men on the ban on blood donation: a cross sectional survey with qualitative interviews. BMJ 2011; 343:d5604.

21 Romeijn B, van Dongen A, Kok G: Reasons for noncompliance in donor risk reporting regarding male-tomale sex. Transfusion 2016, 56;1899-1906.

22 Willson S, Miller K, Seem D, Kuehnert MJ: Cognitive evaluation of the AABB uniform donor history questionnaire. Transfusion 2016;56:1662-1667.

23 Goldman M, Yi QL, Ye X, Tessier L,O’Brien SF: Donor understanding and attitudes about current and potential deferral criteria for high-risk sexual behavior. Transfusion 2011;51:1829-1834.

24 Gray PS, Williamson JB, Karp DA, Dalphin JR:. The Research Imagination: An Introduction to Qualitative and Quantitative Methods. Cambridge, Cambridge University Press, 2007. 
25 Presser S, Couper MP, Lessler JT, Martin E, Martin J, Rothgeb JM, et al: Methods for testing and evaluating survey questions. Public Opin Q 2004;68:109-130.

26 Orton SL, Virvos VJ, Williams AE: Validation of selected donor-screening questions: structure, content, and comprehension. Transfusion 2000;40:1407-1413.

27 Wibeck V, Abrandt-Dahlgren M, Öberg G: Learning in focus groups: an analytical dimension for enhancing focus group research. Qualitative Res 2007;7:249-267

28 Fridey JL, Townsend MJ, Kessler DA, Gregory KR:A question of clarity: redesigning the American Association of Blood Banks Blood Donor History Questionnaire - a chronology and model for donor screening. Transfus Med Rev 2007,21:181-204.

29 Memon A, Bull R: The cognitive interview: its origins, empirical support, evaluation and practical implications. J Community Appl Soc Psychol 1991;1:291-307.

30 Beatty PC, Willis GB: Research synthesis: the practice of cognitive interviewing. Public Opin Q. 2007;71: 287-311.

31 Offergeld R, Heiden M, Stötzer F, Northoff H: Der einheitliche Spenderfragebogen. Hämotherapie 2011;16: 23-27.

32 Arbeitskreis Blut: Stellungnahme des AK Blut. Verwendung eines einheitlichen Fragebogens für Blutund Plasmaspender. Bundesgesundheitsbl Gesundheitsforsch Gesundheitsschutz 2010;53:862-862.

33 Robert Koch-Institut: KABaSTI Studie des RKI zu Wissen, Einstellungen und Verhalten von MSM. Zusammenfassung: Epid Bull 2007;23:189-194.

34 Bundeszentrale für gesundheitliche Aufklärung: AIDS im öffentlichen Bewusstsein der Bundesrepublik Deutschland 2014. www.forschung.sexualaufklaerung. de/forschungsthemen/sexualverhalten/projekt/aidsim-oeffentlichen-bewusstsein-der-bundesrepublikdeutschland-2014/?tx_bzgaforschung_projects[action] = findingse $r$ Hash $=2053 d 22659 e e 13 a 4 c a 96 c 5191$ f $2 b 7885$ (last accessed July 6, 2017).

35 Houareau C, Deitenbeck R, Sümnig A, Moeller A, Saadé C, Stötzer F, Heiden M, Northoff H, Offergeld R Good feasibility of the new german blood donor questionnaire. Transfus Med Hemother 2017;44; DOI: $10.1159 / 000477942$
36 Müller-Steinhardt $M$, Weidmann $C$, Wiesneth $M$, Weck E, Seifried E, Brade J, Klüter H: Donor deferral rates after the implementation of a new German blood donor questionnaire. Transfus Med Hemother 2012; 39:17-22.

37 Custer B, Chinn A, Hirschler NV, Busch MP, Murphy EL: The consequences of temporary deferral on future whole blood donation. Transfusion 2007;47:1514-1523.

38 Greinacher A, Weitmann K, Lebsa A, Alpen U, Gloger D, Stangenberg W, Kiefel V, Hoffmann W: A population-based longitudinal study on the implications of demographics on future blood supply. Transfusion 2016:56;2986-2994.

39 Renner J: Neuer Fragebogen bei Blutspende: Hatten Sie schon Sex gegen Geld? Hessische/Niedersächsiche Allgemeine, 2016www.hna.de/lokales/korbach-waldeck/neuer-fragebogen-blutspende-hatten-schon-gegengeld-6909323.html (last accessed July 6, 2017).

40 Jahnel N. Blut: Intime Fragen sind wieder passé. Schwäbische Zeitung 15.06.2011.

41 Weidmann C, Müller-Steinhardt M, Schneider S, Weck E, Klüter H: Donor satisfaction with a new German blood donor questionnaire and intention of the donor to return for further donations. Transfus Med Hemother 2013;40:356-361.

42 Sümnig A, Lembcke H, Weber H, Deitenbeck R, Greffin K, Bux J, Greinacher A: Evaluation of a new German blood donor questionnaire. Vox Sang 2014;106: 55-60.

43 Bagot KL, Murray AL, Masser BM. How can we improve retention of the first-time donor? a systematic review of the current evidence. Transfus Med Rev 2016;30:81-91.

44 O’Brien SF, Osmond L, Choquet K, Yi QL, Goldman M: Donor attention to reading materials. Vox Sang 2015;109:336-342.

45 O’Brien SF, Ram SS, Vamvakas EC, Goldman M: The Canadian Blood Donor Health Assessment Questionnaire: lessons from history, application of cognitive science principles, and recommendations for change. Transfus Med Rev 2007;21:205-222.
46 O’Brien SF, Fan W, Ram SS, Goldman M, Nair RC, Chiavetta JA, Vamvakas EC: Face-to-face interviewing in pre-donation screening: lack of effect on detected human immunodeficiency virus and hepatitis $\mathrm{C}$ virus infections. Transfusion 2006;46:1380-1387.

47 Silvergleid AJ, Leparc GF, Schmidt PJ: Impact of explicit questions about high-risk activities on donor attitudes and donor deferral patterns. Transfusion 1989; 29:362-364.

48 Weisband S, Kiesler S: Self disclosure on computer forms: meta-analysis and implications. Conference on Human Factors in Computing Systems - Proceedings 1996:3-10. ACM.

49 Katz LM, Cumming PD, Wallace EL: Computer based blood donor screening: a status report. Transfus Med Rev 2007;21:13-25.

50 Blatyta PF, Custer B, Gonçalez TT, Birch R, Lopes ME, Lopes Ferreira MI, Carneiro Proietti AB, Cerdeira Sabino E, Page K, de Almeida-Neto C; for the NHLBI Retrovirus Epidemiology Donor Study-II (REDS-II), International Component: Undisclosed human immunodeficiency virus risk factors identified through a computer-based questionnaire program among blood donors in Brazil. Transfusion 2013;53:2734-274.

51 Goldman M, Ram SS, Yi QL, Mazerall J, O'Brien SF The donor health assessment questionnaire: potential for format change and computer-assisted self-interviews to improve donor attention. Transfusion 2007; 47:1595-1600.

52 Food and Drug Administration: Implementation of Acceptable Full Length and Abbreviated Donor History Questionnaires and Accompanying Materials for Use in Screening Donors of Blood and Blood Components. 2016. www.fda.gov/downloads/BiologicsBloodVaccines/ GuidanceComplianceRegulatoryInformation/Guidances/ Blood/UCM273685.pdf (last accessed July 6, 2017). 